\title{
HÆMODYNAMIC CONSEQUENCES OF CORONARY HEART DISEASE WITH OBSERVATIONS DURING ANGINAL PAIN AND ON THE EFFECT OF NITRO-
GLYCERINE
}

\author{
BY \\ OTTAR MÜLLER AND KARL RØRVIK \\ From the University Institute for Respiratory Physiology (Dept. III) and Department VIII, Ullevaal Hospital, Oslo \\ Received October 22, 1957
}

It is known from previous investigations (Lewis et al. 1953) that patients with coronary heart disease, previous myocardial infarction, and an enlarged heart may show the usual signs of left ventricular failure with increased pulmonary vascular pressures and a tendency to reduced cardiac output. To our knowledge, no systematic investigations of cardiac output and pressures in the lesser circulation have been made in patients with coronary heart disease and a normal-sized heart, with anginal pain as the main symptom. Nor have any observations been published from the same patients when free from pain and when complaining of pain, either spontaneous or induced by exercise.

It is generally believed that the administration of nitro-glycerine leads to a dilatation of coronary vessels. An increase in coronary blood flow subsequent to nitro-glycerine has been demonstrated in animals (Gregg, 1950), and its effect on anginal pain due to coronary heart disease in man has also been attributed to its influence on the coronary blood flow (Wayne and Laplace, 1933; Russek et al., 1955). However, there are no observations by cardiac catheterization on the effect of nitro-glycerine on the left ventricular function and the lesser circulation in man. This research has been designed to fill these apparent gaps.

Material and Methods. Twenty-four patients with coronary heart disease have been studied by cardiac catheterization, one of them twice at an interval of a year (observations 8 and 9); 20 had electrocardiographic signs and a history of previous myocardial infarction. In these patients catheterization was performed from one month (in one) to eight years after the last known infarction. The four patients without known infarction all had typical anginal pain and also cardiographic changes of angina on staircase tests.

The age of the patients, 3 of whom were women, varied from 45 to 84 years. In 3 (Cases 2, 7, and 24) the blood pressure had been raised but was, as in the others, normal at the time of the investigation. Cases 3 and 7 had diabetes mellitus, Cases 8 and 24 had xanthomatosis, and Case 24 had thrombocytopenia. All had regular sinus rhythm during the investigations.

With the patients resting on the table, pressure in the right atrium, pulmonary artery, and pulmonary artery wedge position (pulm. capillary pressure) were recorded. The oxygen consumption was determined by spirometry, using room air. Blood samples were obtained from the pulmonary artery (mixed venous blood) and from a peripheral artery, usually the brachial, by an indwelling needle.

The patients were investigated during exercise as well as at rest in 15 instances. The exercise consisted of bicycling in recumbency on an ergometer for at least $5 \frac{1}{2}$ minutes in 10 cases, but in the other 5 it had to be discontinued after $2 \frac{1}{2}$ to 4 minutes because of excessive dyspnoa or anginal pain. A Statham strain-guage coupled to an AC-DC amplifier and a Brush oscillograph was used for the pressure recordings, and the pressures related to a point $10 \mathrm{~cm}$. in front of the patient's back. Manometric (van Slyke) and spectrophotometric (Refsum et al., 1956) methods were used for the oxygen determinations in the blood samples. Cardiac output was determined according to the direct Fick principle and expressed in litres per minute per square meter body surface (cardiac index). 


\section{RESULTS}

(a) Patients with dyspnea but no angina. Eight patients with previous infarction and with dyspnœa as the main complaint were selected for studies (Table I). Four of them were observed during moderate exercise as well as at rest. All had experienced nocturnal attacks of breathlessness, though in Case 1 this occurred only in combination with tachycardia (? paroxysmal). All showed enlarged hearts by X-ray (more than 500-540 ml./m. ${ }^{2}$ for men; Amundsen, 1956), except Case 3 with a heart size at the upper limit of normal.

TABLE I

Patients with Dyspncea as the Main Symptom and with Enlarged Hearts

\begin{tabular}{|c|c|c|c|c|c|c|c|c|c|c|c|c|c|}
\hline \multirow[b]{2}{*}{ No. } & \multirow[b]{2}{*}{ Age } & \multirow{2}{*}{$\begin{array}{l}\text { Heart } \\
\text { vol. in } \\
\mathrm{ml} . / \mathrm{m} .^{2}\end{array}$} & \multicolumn{6}{|c|}{ Rest } & \multicolumn{5}{|c|}{ Exercise } \\
\hline & & & $\begin{array}{l}\mathrm{O}_{2} \text { cons. } \\
\mathrm{ml} . / \mathrm{m} .^{2}\end{array}$ & CI & $\mathrm{RAP}_{\mathbf{m}}$ & $\mathrm{PAP}_{\mathrm{m}}$ & $\mathrm{PCP}_{\mathrm{m}}$ & $\begin{array}{l}\mathrm{MVB} \\
\mathrm{O}_{2} \%\end{array}$ & $\begin{array}{c}\text { Incr. } \\
\mathrm{O}_{2} \text { cons. }\end{array}$ & $\mathrm{CI}$ & $\mathrm{PAP}_{\mathrm{m}}$ & $\mathrm{PCP}_{\mathrm{m}}$ & $\begin{array}{l}\mathrm{MVB} \\
\mathrm{O}_{2} \%\end{array}$ \\
\hline 1 & 49 & 600 & 150 & $4 \cdot 4$ & 5 & (RV 36/4) & & $74 \cdot 0$ & & & & & \\
\hline 2 & 58 & 590 & 155 & $3 \cdot 1$ & 4 & 31 & 25 & $57 \cdot 0$ & & & & & \\
\hline 3 & 60 & 510 & 145 & $2 \cdot 5$ & 4 & 25 & & $63 \cdot 0$ & & & & & \\
\hline 4 & 75 & $\mathrm{LV}+$ & 160 & $4 \cdot 2$ & 9 & 34 & 25 & $69 \cdot 3$ & & & & & \\
\hline 5 & 61 & 670 & 165 & $1 \cdot 8$ & 9 & 35 & 19 & $59 \cdot 7$ & 180 & 1.9 & 45 & 35 & $42 \cdot 0$ \\
\hline 6 & 63 & 760 & 160 & $3 \cdot 5$ & 6 & 40 & 32 & $60 \cdot 0$ & & & 62 & 45 & $51 \cdot 1$ \\
\hline 7 & 61 & 650 & 150 & $4 \cdot 3$ & $4 \frac{1}{2}$ & 27 & 17 & $64 \cdot 7$ & 300 & $4 \cdot 3$ & 51 & 39 & $52 \cdot 5$ \\
\hline 8 & 53 & 650 & 160 & $2 \cdot 9$ & 6 & 34 & $27 \frac{1}{2}$ & $69 \cdot 1$ & 400 & $4 \cdot 0$ & 60 & $37 \frac{1}{2}$ & $51 \cdot 1$ \\
\hline
\end{tabular}

All patients were men except Case 4. All had nocturnal dyspnœa. $\mathrm{O}_{2}$ cons.=Oxygen consumption, ml. per minute per square metre body surface. $\mathrm{RAP}_{\mathrm{m}}, \mathbf{P A P}_{\mathrm{m}}, \mathbf{R C} \mathrm{P}_{\mathrm{m}}=$ Mean right atrial, pulmonary arterial, and pulmonary capillary pressures in $\mathrm{mm}$. $\mathrm{Hg}$. MVB $\mathrm{O}_{2} \%=$ Oxygen saturation of mixed venous blood. Incr. $\mathrm{O}_{2}$ cons.=Increase of oxygen consumption during exercise, ml. per minute. $\mathrm{CI}=$ Cardiac Index. Case 6: Exercise $50 \mathrm{~kg}$. m. $/ \mathrm{min}$. for $2 \frac{1}{2}$ minutes.

In all six patients where pulmonary capillary pressure was obtained, this was increased above normal limits $(14 \mathrm{~mm} . \mathrm{Hg})$ even at rest, with a parallel increase in pulmonary artery pressure. Two others (Cases 1 and 3 ) showed right ventricular and pulmonary artery pressures just above the upper limit of normal. Although only one (Case 5) has a subnormal cardiac index, five showed resting oxygen saturation in mixed venous blood below 65 per cent. The right atrial mean pressure tended to be high, being $6 \mathrm{~mm}$. $\mathrm{Hg}$ or more in four, while in two, who had the smallest hearts, it was within normal limits.

In four patients exercised, pulmonary capillary pressures increased still further and ranged from 35 to $45 \mathrm{~mm}$. $\mathrm{Hg}$. In one (Case 6) where it reached the highest level, the exercise test had to be discontinued after $2 \frac{1}{2}$ minutes because of excessive dyspnœa although the effort was very moderate. In two of three cases where cardiac output was measured, no increase occurred during exercise.

(b) Angina with previous myocardial infarction. Eleven patients with previous myocardial infarction and with anginal pain as the dominant symptom were catheterized, 8 of them during exercise as well as at rest (Table II). Six had experienced nocturnal attacks of anginal pain, the remainder only on varying degrees of effort. All except one had X-ray examination, and all these showed heart volumes below or within the upper limit of normal.

Only one (Case 9) of ten patients had an abnormally raised pulmonary capillary pressure at rest. Five, however, had pressures in the upper, normal region (11-12 mm. Hg). None had subnormal cardiac outputs, but two (Cases 15 and 17) had a cardiac index near the lower, normal limit for their age (Brandfonbrener et al., 1955). One man, 84 years old, in whom no determination of oxygen 
TABLE II

Patients with Anginal Pain as the Main Symptom and an Earlier Infarction and a Normal-sized Heart

\begin{tabular}{|c|c|c|c|c|c|c|c|c|c|c|c|c|c|c|c|c|}
\hline \multirow[b]{2}{*}{ No. } & \multirow[b]{2}{*}{ Age } & \multirow{2}{*}{$\begin{array}{l}\text { Ang. } \\
\text { pain }\end{array}$} & \multirow{2}{*}{$\begin{array}{c}\text { Heart } \\
\text { vol. in } \\
\mathrm{ml} . / \\
\mathrm{m} .{ }^{2}\end{array}$} & \multicolumn{6}{|c|}{ Rest } & \multicolumn{7}{|c|}{ Exercise } \\
\hline & & & & $\begin{array}{l}\mathrm{O}_{2} \text { cons. } \\
\mathrm{ml} . / \mathrm{m} .{ }^{2}\end{array}$ & $\mathrm{CI}$ & $\mathrm{PAP}_{\mathrm{m}}$ & $\mathrm{PCP}_{\mathrm{m}}$ & $\mid$\begin{tabular}{|l|}
$\mathrm{MVB}$ \\
$\mathrm{O}_{2} \%$
\end{tabular} & $\begin{array}{c}\text { Heart } \\
\text { rate }\end{array}$ & $\begin{array}{c}\text { Incr. } \\
\mathrm{O}_{2} \text { cons. }\end{array}$ & $\mathrm{CI}$ & $\mathrm{PAP}_{\mathrm{m}}$ & $\mathrm{PCP}_{\mathrm{m}}$ & $\mid \begin{array}{l}\mathrm{MVB} \\
\mathrm{O}_{2} \%\end{array}$ & $\begin{array}{c}\text { Heart } \\
\text { rate }\end{array}$ & A.P \\
\hline 9 & 52 & +++ & 500 & 160 & $3 \cdot 3$ & 24 & 16 & $69 \cdot 0$ & 68 & & & & & & & \\
\hline 10 & 84 & +++ & & & $\begin{array}{r}\text { (A-Vd. } \\
4.9)\end{array}$ & 13 & & $58 \cdot 0$ & 70 & & & & & & & \\
\hline 11 & 53 & +++ & 420 & 175 & $5 \cdot 0$ & 22 & 6 & $69 \cdot 2$ & 85 & & & & & & & \\
\hline 12 & 64 & +++ & 390 & 140 & $4 \cdot 9$ & 19 & 11 & $77 \cdot 0$ & 67 & 450 & $5 \cdot 2$ & 43 & & $52 \cdot 3$ & 100 & $+?$ \\
\hline 13 & 59 & +++ & 360 & 150 & $3 \cdot 9$ & 18 & 12 & $73 \cdot 5$ & 75 & 510 & & 45 & 32 & & 106 & + \\
\hline 14 & 59 & +++ & 280 & 145 & $3 \cdot 7$ & 17 & 9 & 71.9 & 75 & & & 40 & 33 & $59 \cdot 1$ & 96 & + \\
\hline 15 & 66 & ++ & 460 & 140 & $2 \cdot 8$ & 19 & 12 & $65 \cdot 9$ & 62 & 280 & $4 \cdot 0$ & 32 & 25 & $58 \cdot 6$ & 80 & + \\
\hline 16 & 49 & ++ & 510 & 145 & $3 \cdot 0$ & 25 & 11 & $69 \cdot 9$ & 62 & & & 35 & & $59 \cdot 9$ & 95 & - \\
\hline 17 & 63 & ++ & 450 & 140 & $2 \cdot 6$ & 18 & 11 & $67 \cdot 0$ & 60 & & & 41 & 27 & $59 \cdot 2$ & 70 & + \\
\hline 18 & 45 & ++ & 450 & 130 & $3 \cdot 3$ & 15 & 8 & $70 \cdot 0$ & 75 & 250 & 4.9 & 25 & 14 & $61 \cdot 9$ & 86 & - \\
\hline 19 & 46 & + & 435 & 135 & $3 \cdot 0$ & 17 & 10 & $71 \cdot 0$ & 62 & 335 & $4 \cdot 4$ & 27 & (20) 15 & $59 \cdot 3$ & 83 & - \\
\hline
\end{tabular}

All patients were men. The work was $110 \mathrm{~kg}$. m. $/ \mathrm{min}$. for Case $14,90 \mathrm{~kg} . \mathrm{m} . / \mathrm{min}$. for Case 16 , and $60 \mathrm{~kg}$. m. $/ \mathrm{min}$. for Case 17. It was done for $5 \frac{1}{2}$ minutes by Case 16 and for 3 minutes by the other two. Ang. pain=history of anginal pain, $+=$ pain on heavy effort only, $++=$ pain on slight to moderate effort, $+++=$ Angina decubitus. A.P.=Anginal pain during the exercise test. See also legend Table I.

consumption was obtained, was the only patient in the group with an oxygen saturation in mixed venous blood below 65 per cent: an arterio-venous oxygen difference of $49 \mathrm{ml}$./1. did not, however, suggest an abnormally low cardiac output for his age.

Of the 8 patients exercised, 6 showed abnormal increases of the pulmonary vascular pressure, with an increase in pulmonary capillary pressure in the four where this was recorded. All except one of these experienced typical or probable anginal pain during the exercise test.

Two patients only had normal or near normal hæmodynamics at the end of the exercise period: neither had a constricting sensation in the chest during the test. In one (Case 19) pulmonary capillary pressures increased to $20 \mathrm{~mm}$. during the first two minutes of exercise, but thereafter declined steadily and measured $15 \mathrm{~mm}$. at the end of the six minutes of exercise.

In distinction to those with an enlarged heart and dyspnœa as the main symptom, all patients in this group showed an increase in cardiac output during exercise, as judged from cardiac index, arterio-venous oxygen difference, or oyxgen saturation in mixed venous blood.

(c) Angina without recognizable infarction. Three patients with coronary heart disease and anginal pain, but without known infarction were observed at rest and during exercise (Table III). All three had normal hæmodynamics at rest. The rather low cardiac index in Case 20 is normal for the patient's age according to Brandfonbrener et al. (1955)

All patients, however, developed an abnormally raised pulmonary capillary pressure during exercise. Only one of the three experienced constricting pain during the test. The heart rates increased only moderately. Only one exercised for a period long enough to obtain data for cardiac output determination (Case $21 ; \mathrm{CI}, 4,2$ ). The arterio-venous oxygen difference in the others did not suggest an abnormal cardiac output response to exercise. 
$\mathrm{mm} \mathrm{Hg}$

beats $/ \mathrm{min}$

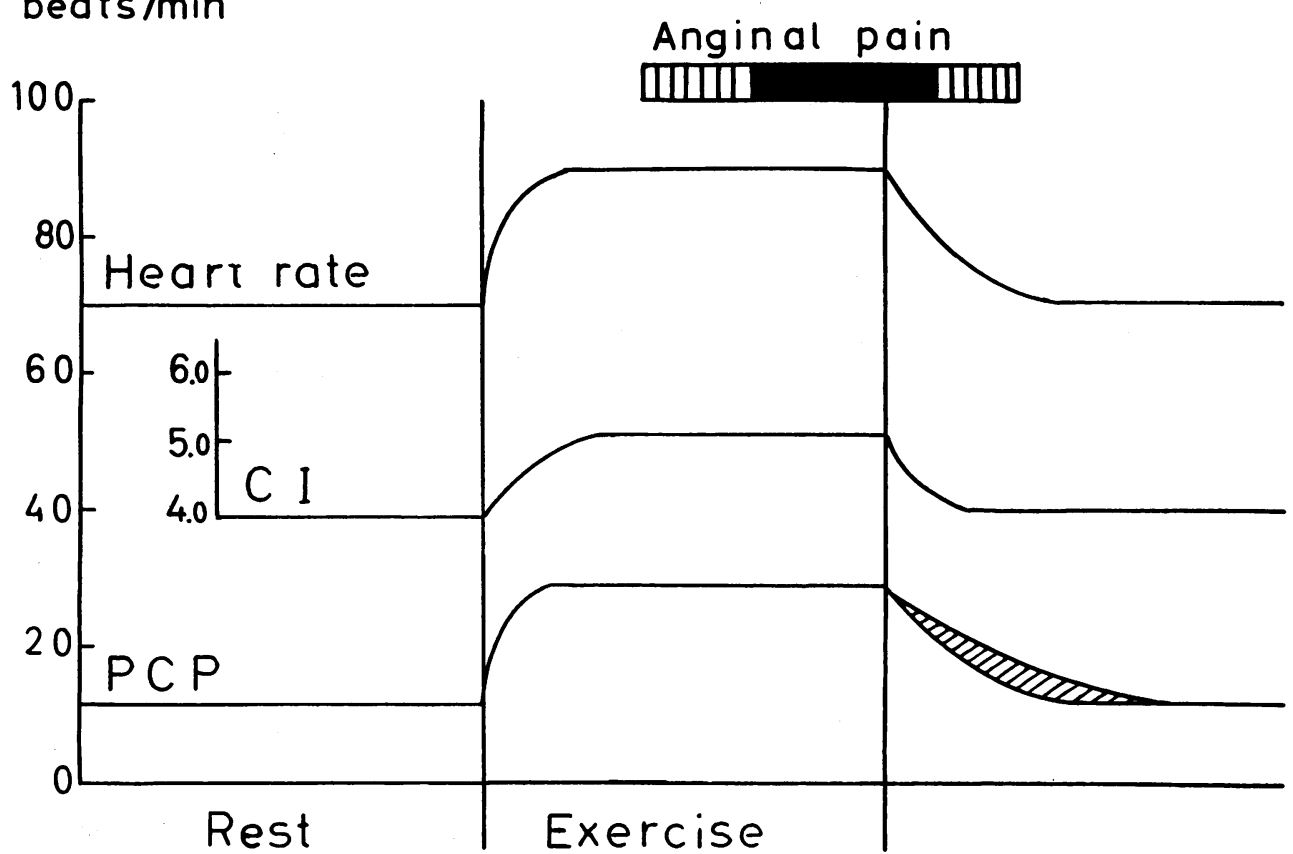

Fig. 1.-Reaction to exercise precipitating anginal pain. Patients with earlier infarctions and normal-size hearts. Schematic drawing based on observations from Cases 12, 13, 14, 15, and 17.

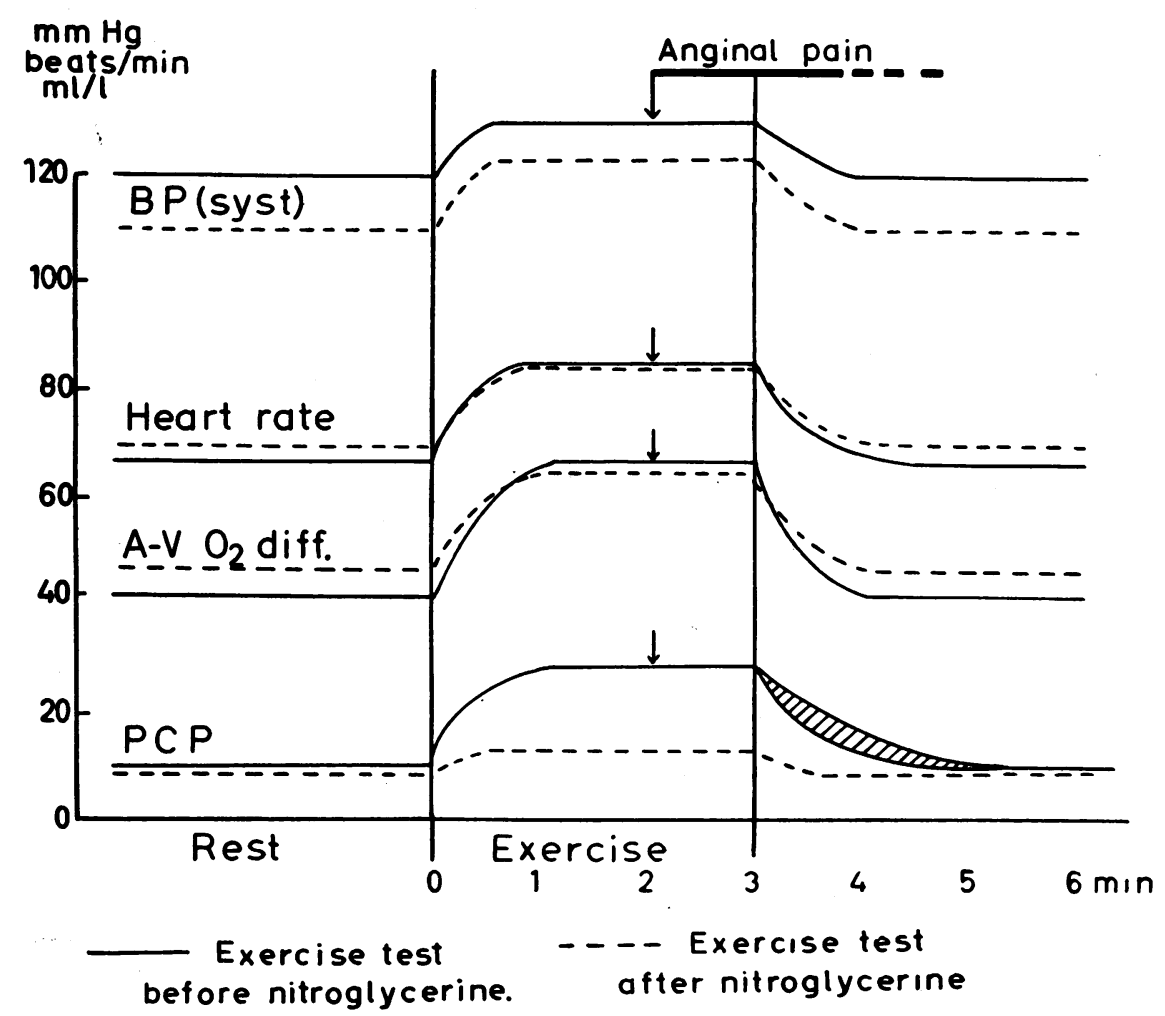

FIG. 2.-Reaction to exercise before and after nitro-glycerine. Patients with normal-sized hearts. Schematic drawing based on observations from Cases 14, 17, and 22. 
(d) Spontaneous attacks of anginal pain. Two patients, both women, one with and one without known infarction, were observed at the height of a spontaneous attack of anginal pain when resting on the table (Table IV). Both had a heart of normal size. Both had subnormal hæmoglobin concentrations, one being treated with anticoagulants and the other having thrombocytopenia. Both had normal pulmonary vascular pressures when free of pain and at rest. During the attack of anginal pain both showed gross increases of pulmonary capillary pressures. Simultaneously, rises in heart rate of about 15 beats a minute occurred, together with an increase in oxygen saturation of mixed venous blood indicating an increase of cardiac output of 20-25 per cent if the oxygen consumption remained unchanged. During a similar attack in one of them (Case 24) the systolic peripheral blood pressure was observed to increase by $25 \mathrm{~mm}$.

TABLE III

Patients with Anginal Pain as the Main Symptom but Without an Earlier Infarction

\begin{tabular}{|c|c|c|c|c|c|c|c|c|c|c|c|c|c|c|c|}
\hline \multirow[b]{2}{*}{ No. } & \multirow[b]{2}{*}{ Age } & \multirow[b]{2}{*}{$\begin{array}{l}\text { Ang. } \\
\text { pain }\end{array}$} & \multirow{2}{*}{$\begin{array}{l}\text { Heart } \\
\text { vol. in } \\
\mathrm{ml} . / \mathrm{m} .^{2}\end{array}$} & \multicolumn{6}{|c|}{ Rest } & \multicolumn{6}{|c|}{ Exercise } \\
\hline & & & & $\begin{array}{l}\mathrm{O}_{2} \text { cons. } \\
\mathrm{ml} . / \mathrm{m}^{2}\end{array}$ & CI & $\begin{array}{l}\mathrm{A}-\mathrm{V} \\
\mathrm{O}_{2} \mathrm{~d}\end{array}$ & $\mathrm{PAP}_{\mathrm{m}}$ & $\mathbf{P C P}_{\mathbf{m}}$ & $\begin{array}{c}\text { Heart } \\
\text { rate }\end{array}$ & $\begin{array}{l}\mathrm{A}-\mathrm{V} \\
\mathrm{O}_{2} \mathrm{~d} .\end{array}$ & $\mathbf{P A P}_{\mathrm{m}}$ & $\mathrm{PCP}_{\mathrm{m}}$ & $\begin{array}{c}\text { BP } \\
\text { incr. }\end{array}$ & $\left|\begin{array}{c}\text { Heart } \\
\text { rate }\end{array}\right|$ & A.P. \\
\hline 20 & 72 & + & 460 & 115 & $2 \cdot 3$ & $5 \cdot 1$ & 16 & 10 & 50 & $7 \cdot 5$ & 37 & 28 & & 72 & - \\
\hline 21 & 55 & +++ & 370 & 130 & $3 \cdot 1$ & $4 \cdot 3$ & 15 & 6 & 75 & $5 \cdot 8$ & 21 & 16 & 25 & 80 & - \\
\hline 22 & 50 & ++ & 380 & 125 & $3 \cdot 5$ & $3 \cdot 5$ & 14 & 10 & 66 & $6 \cdot 6$ & 34 & 28 & 15 & 88 & + \\
\hline
\end{tabular}

All patients were men. Exercise was between 80 and $90 \mathrm{~kg} . \mathrm{m} . / \mathrm{min}$. for 3,6 , and 3 minutes respectively. A-V $\mathrm{O}_{2} \mathrm{~d}$. $=$ Arterio-venous oxygen difference, volume per cent. BP incr.=Increase of palpatory systolic systemic blood pressure, mm. Hg. See also legend Tables I and II.

TABLE IV

Spontaneous Attacks of Anginal Pain

\begin{tabular}{|c|c|c|c|c|c|c|c|c|c|c|c|c|}
\hline \multirow[b]{2}{*}{ No. } & \multirow[b]{2}{*}{ Age } & \multirow{2}{*}{$\begin{array}{l}\text { Heart } \\
\text { vol. in } \\
\mathrm{ml} . / \mathrm{m} .^{2}\end{array}$} & \multicolumn{6}{|c|}{ Patients free from pain } & \multicolumn{4}{|c|}{ During anginal pain } \\
\hline & & & $\begin{array}{l}\mathrm{O}_{2} \text { con. } \\
\mathrm{ml} . / \mathrm{m}^{2}\end{array}$ & $\mathrm{CI}$ & $\begin{array}{l}\mathrm{MVB} \\
\mathrm{O}_{2} \%\end{array}$ & $\mathrm{PAP}_{\mathrm{m}}$ & $\mathrm{PCP}_{\mathrm{m}}$ & $\begin{array}{l}\text { Heart } \\
\text { rate }\end{array}$ & $\begin{array}{l}\mathrm{MVB} \\
\mathrm{O}_{2} \%\end{array}$ & PAP $_{m}$ & $\mathrm{PCP}_{\mathrm{m}}$ & $\begin{array}{c}\text { Heart } \\
\text { rate }\end{array}$ \\
\hline 23 & 46 & 400 & 145 & $3 \cdot 7$ & $60 \cdot 3$ & 13 & 8 & 75 & $66 \cdot 3$ & & 35 & 93 \\
\hline 24 & 66 & 350 & 125 & $3 \cdot 0$ & $64 \cdot 8$ & 25 & 14 & 77 & $72 \cdot 2$ & 43 & 34 & 92 \\
\hline
\end{tabular}

Both patients were women. Case 23 had a $\mathrm{Hb}$. of $64 \%$, an old infarct, and xanthomatosis. Case 24 had a $\mathrm{Hb}$. of $79 \%$. See legend to Tables I and II.

(e) Effect of nitro-glycerine. Four patients, two with and two without myocardial infarction, were observed at rest and during exercise, before as well as 10 to 14 minutes after the administration of $0.5 \mathrm{mg}$. of nitro-glycerine (Table V). All four had anginal pain as the main symptom, a normalsized heart, and ST-T depression after standard staircase tests.

All patients had normal or near normal hæmodynamics at rest. No systematic changes were observed at rest after nitro-glycerine, except that the pulmonary capillary pressure, which had been normal, showed a fall of $1-2 \mathrm{~mm}$. in all patients and the peripheral systolic blood pressure declined 0-10 mm.

During the exercise test before nitro-glycerine all four patients developed abnormally increased pulmonary capillary pressures, $16 \mathrm{~mm}$. in the only patient without anginal pain, 27, 28, and $33 \mathrm{~mm}$. in the three who developed constricting pain during the test. In these three, the pain appeared

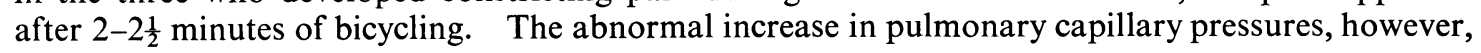


TABLE V

Effect of Nitro-glycerine in Patients whose Main Symptom was Anginal Pain

\begin{tabular}{|c|c|c|c|c|c|c|c|c|c|c|c|c|c|c|c|c|}
\hline \multirow[b]{2}{*}{ No. } & \multirow[b]{2}{*}{$\begin{array}{l}\text { Age } \\
\text { sex }\end{array}$} & \multirow{2}{*}{$\begin{array}{l}\text { Heart } \\
\text { vol. in } \\
\mathrm{ml} . / \mathrm{m}^{2}\end{array}$} & & \multicolumn{6}{|c|}{ Rest } & \multicolumn{7}{|c|}{ Exercise } \\
\hline & & & & CI & $\begin{array}{l}\mathrm{A}-\mathrm{V} \\
\mathrm{O}_{2} \mathrm{~d}\end{array}$ & $\mathbf{P A P}_{\mathbf{m}}$ & $\mathbf{P C P}_{\mathbf{m}}$ & $\begin{array}{c}\text { Heart } \\
\text { rate }\end{array}$ & $\begin{array}{l}\text { BP } \\
\text { (s) }\end{array}$ & $\begin{array}{l}\mathrm{A}-\mathrm{V} \\
\mathrm{O}_{2} \mathrm{~d} .\end{array}$ & $\mathbf{P A P}_{\mathbf{m}}$ & $\mathbf{P C P}_{\mathbf{m}}$ & $\begin{array}{c}\text { Heart } \\
\text { rate }\end{array}$ & $\begin{array}{l}\text { Work } \\
\text { load }\end{array}$ & $\begin{array}{c}\text { BP } \\
\text { (s) }\end{array}$ & A.P. \\
\hline \multirow{2}{*}{14} & \multirow{2}{*}{$\begin{array}{l}59 \\
\mathrm{~m} .\end{array}$} & \multirow{2}{*}{280} & Before & $3 \cdot 7$ & $3 \cdot 7$ & 17 & 9 & 75 & 140 & 6.7 & 40 & 33 & 96 & $\begin{array}{c}110 \\
3\end{array}$ & 150 & + \\
\hline & & & After & & $4 \cdot 6$ & 15 & 7 & 69 & 135 & $6 \cdot 7$ & 21 & 11 & 97 & $\begin{array}{c}115 \\
3\end{array}$ & 155 & - \\
\hline \multirow{2}{*}{17} & \multirow{2}{*}{$\begin{array}{l}63 \\
\mathrm{~m} .\end{array}$} & \multirow{2}{*}{450} & Before & $2 \cdot 6$ & $5 \cdot 4$ & 18 & 11 & 60 & 115 & $7 \cdot 0$ & 41 & 27 & 70 & $\begin{array}{r}60 \\
3\end{array}$ & 125 & + \\
\hline & & & After & & $5 \cdot 3$ & 18 & 9 & 62 & 105 & $6 \cdot 7$ & 23 & 13 & 68 & $\begin{array}{l}60 \\
3\end{array}$ & 110 & - \\
\hline \multirow{2}{*}{21} & \multirow{2}{*}{$\begin{array}{l}55 \\
\mathrm{~m} .\end{array}$} & \multirow{2}{*}{370} & Before & $3 \cdot 1$ & $4 \cdot 3$ & 15 & 6 & 75 & 110 & $5 \cdot 8$ & 21 & 16 & 80 & $\begin{array}{l}85 \\
6\end{array}$ & 135 & - \\
\hline & & & After & & $4 \cdot 4$ & 12 & 4 & 88 & 105 & $6 \cdot 1$ & 17 & 7 & 75 & $\begin{array}{l}90 \\
6\end{array}$ & 130 & - \\
\hline \multirow{2}{*}{22} & \multirow{2}{*}{$\begin{array}{l}52 \\
\mathrm{~m} .\end{array}$} & \multirow{2}{*}{380} & Before & $3 \cdot 5$ & $3 \cdot 5$ & 14 & 10 & 66 & 100 & $6 \cdot 6$ & 34 & 28 & 88 & $\begin{array}{l}80 \\
3\end{array}$ & 115 & + \\
\hline & & & After & & $4 \cdot 2$ & 16 & 9 & 78 & 100 & $6 \cdot 1$ & 19 & 14 & 86 & $\begin{array}{l}90 \\
3\end{array}$ & 105 & - \\
\hline
\end{tabular}

Cases 14 and 17 had previous cardiac infarction and the other two had not. BP (s)=Palpatory systolic systemic blood pressure, $\mathrm{mm}$. $\mathrm{Hg}$. Work load $=\mathrm{Kg}$. $\mathrm{m}$. $/ \mathrm{min}$. The duration of exercise was 3 minutes in all except Case 21 where it was 6 minutes. See also legends Tables I and II.

was present after only one minute of exercise. In Case 22 the pain increased in intensity for 2-3 minutes after the exercise was stopped and nitro-glycerine administered: during this period the mean pulmonary artery pressure continued to increase and reached a maximum of $52 \mathrm{~mm}$. with a diastolic pressure of $42 \mathrm{~mm}$. The pressures did not fall to the level before exercise until 6 minutes after the exercise was stopped.

During the same or slightly increased exercise 10 to 14 minutes after the administration of nitroglycerine, the pulmonary capillary pressure remained within normal limits in all four patients. The arterio-venous oxygen difference was remarkably similar before and after nitro-glycerine in three of the four, indicating similar trends in cardiac output. In the fourth a smaller oxygen difference suggested a higher cardiac output during the second exercise test. The heart rates were also remarkably constant. The dose of nitro-glycerine was not such as to lower the arterial pressure significantly, and in fact the systolic arterial pressure rose with exercise in all cases.

\section{Discussion}

Our observations in the group of patients with previous infarction, an enlarged heart, and dyspnœa as their main symptom are in accord with the findings of previous investigators (Lewis et al., 1953). Signs of left ventricular failure with increased pressures throughout the lesser circulation and a tendency to subnormal cardiac outputs were found at rest, with much greater deviations from normal during exercise. In all cases exercised, pulmonary capillary pressures rose to levels where pulmonary cdema is imminent (Gorlin et al., 1951), and no increase in cardiac output occurred in two of the three.

In contrast to the above group, most patients with previous infarction, a heart of normal size, and varying degrees of anginal pain showed essentially normal hæmodynamics at rest and when free of 
pain. The only exceptions were a man of 84 with a subnormal resting oxygen saturation in mixed venous blood, but with an arterio-venous oxygen difference suggestive of a normal cardiac output for his age, and a patient with a borderline heart size and a pulmonary capillary pressure just above the upper limit of normal. All the others in this group had normal pulmonary capillary pressures, though five of the nine were in the upper normal region, and had normal cardiac outputs for their ages.

Similar, essentially normal findings were obtained at rest and when free from pain in patients with varying degrees of anginal pain as the main complaint, but without known infarction. The transition of a patient from one group to the other in the course of a year without a new, major infarction is illustrated in Table VI. With an increase in pulmonary vascular pressures and a fall, albeit small, in cardiac output, there was a change in symptoms from mainly pain and only slight dyspnœa on effort, to dyspnœa both on effort and at night with only slight pain, and an increase in heart volume.

The observations during exercise in patients with hearts of normal size were essentially similar whether they had a history or signs of previous infarction or not: signs of varying degrees of left ventricular failure with raised pulmonary capillary and/or arterial pressures were observed in nine of eleven patients exercised. The nine with signs of left ventricular failure comprised all patients who experienced anginal pain during the exercise test together with three who did not. In patients where anginal pain was precipitated, the rise in pulmonary capillary pressure was observed to precede the sensation of pain which usually appeared after two or three minutes of exercise, while the rise in pressure was recorded after one minute.

TABLE VI

Observations on a Patient, One and Two Years after Myocardial Infarction

\begin{tabular}{|c|c|c|c|c|c|c|c|c|c|}
\hline \multirow[b]{2}{*}{$\begin{array}{l}\text { After } \\
\text { infarct }\end{array}$} & \multicolumn{2}{|c|}{ Pain } & \multicolumn{2}{|c|}{ Dyspnœa } & \multirow{2}{*}{$\begin{array}{l}\text { Heart } \\
\text { vol. in } \\
\mathrm{ml} . / \mathrm{m} .^{2}\end{array}$} & \multicolumn{4}{|c|}{ Rest } \\
\hline & Noct. & $\begin{array}{c}\text { On } \\
\text { effort }\end{array}$ & Noct. & $\begin{array}{c}\text { On } \\
\text { effort }\end{array}$ & & $\mathrm{O}_{2}$ cons. & CI & $\mathbf{P A P}_{\mathrm{m}}$ & $\mathrm{PCP}_{\mathrm{m}}$ \\
\hline 1 year & + & ++ & - & + & 500 & 160 & $3 \cdot 3$ & 24 & $16 \cdot 0$ \\
\hline 2 years & - & + & + & $+t$ & 600 & 160 & $2 \cdot 9$ & 34 & $27 \cdot 5$ \\
\hline
\end{tabular}

See legend to Tables I and II.

Neither of the two patients without signs of left ventricular failure (indicated by increased pulmonary capillary pressures) at the end of the exercise period, experienced anginal pain during the test. One of them (Case 19) developed a raised pulmonary capillary pressure during the first two minutes of exercise. The pressure, however, thereafter declined and approached the upper limit of normal at the end of the exercise period.

In all cases with a normal-size heart the cardiac output response to exercise seemed to be within normal limits as judged from cardiac index, arterio-venous oxygen difference, and oxygen saturation in mixed venous blood, irrespective of whether there was failure of the left ventricle or not.

The two patients observed at the height of a spontaneous attack of anginal pain both showed transitory, gross signs of left ventricular failure with increase of pulmonary capillary pressures up to levels where pulmonary odema may develop (Gorlin et al., 1951). It seems therefore that the anginal state generally is combined with varying degrees of left ventricular failure, whether the pain is precipitated by effort or is spontaneous. If precipitated by effort, it is usually preceded by the signs of left ventricular failure, which may also develop without any constricting sensations.

A slight fall in pulmonary capillary pressure $(1-2 \mathrm{~mm}$. $\mathrm{Hg}$ ) was the only systematic alteration observed in the lesser circulation 10 minutes after nitro-glycerine was given to four patients with normal heart sizes-when resting on the table. During exercises, however, the changes in hæmodynamics before and after nitro-glycerine were striking. Before nitro-glycerine was given all four 
patients developed abnormally raised pulmonary capillary pressures and signs of left ventricular failure during exercise. After nitro-glycerine they all tolerated the same or slightly heavier work without abnormal rise in pulmonary capillary pressures. In face of the same or slightly increased amount of work performed, the unaltered or slightly reduced arterio-venous oxygen differences observed exclude any significant decrease in cardiac output during the second exercise test. The same holds true for stroke volume as the heart rates also were nearly constant. The pulse pressures in the left ventricle may-in cases without mitral valvular stenosis-be gauged by taking the difference between the pulmonary capillary pressure and the systolic pressure in the peripheral arteries (Epps et al., 1953; Werkö et al., 1953; and Goldberger et al., 1957). It will be noted that this remained constant or even increased. These observations - the unchanged or slightly increased cardiac output, stroke volume, and pressure generated by the left ventricle-together seem to exclude a reduced effective forward left ventricular work or stroke work during the second exercise test as compared to the first. Thus the reduced pulmonary capillary pressure in exercise could not be the consequence of any decline in left ventricular load. Accordingly, the administration of nitro-glycerine, leading in these four cases to a greatly reduced left atrial-and hence left ventricular diastolic-pressure without a simultaneous reduction of effective forward left ventricular work and stroke work, seems to have altered materially the relationship between the amount of left ventricular work and the left ventricular diastolic filling pressure necessary to perform it.

Sarnoff $e t$ al. (1954) reported the observation of a depressive effect on the left ventricular function curve ("Starling curve") of artificial reduction of the blood flow in the left main coronary artery in dogs. As nitro-glycerine is supposed to exert its influence on the myocardium through an augmentation of coronary blood flow (Gregg, 1950), our observations from patients before and after the administration of this drug seem to parallel the findings of Sarnoff $e t$ al. The hæmodynamic changes therefore suggest a reserve of coronary vascular capacity reacting to nitro-glycerine with great influence on the function of the left ventricle. Whether nitro-glycerine causes an exceptional dilatation of vessels of normal calibre or the relaxation of abnormal vasoconstriction cannot be decided from the findings reported here.

\section{ConCLUSIONS}

Twenty-four patients with coronary heart disease, without signs of valvular disease or any rise of blood pressure, have been studied by cardiac catheterization.

Patients with coronary heart disease, previous myocardial infarction, and an enlarged heart, and with dyspnœa as the main symptom generally show hæmodynamic signs of left ventricular failure at rest, with striking accentuation on moderate effort.

Patients with anginal pain as their main complaint and with a heart of normal size mostly have normal hæmodynamic findings at rest when free from pain, whether they have had an old infarct or not. Even if the effective, forward left ventricular stroke work is only moderately increased, anginal pain, whether spontaneous or after exercise, is accompanied by signs of left ventricular failure. This develops before the pain is felt, and in some cases without any constricting sensation. It may continue and even increase after the precipitating factor is removed. Patients in this group usually show normal cardiac output response to moderate exercise, even when left ventricular failure develops (Fig. 1).

In patients with anginal pain as the main symptom and with a heart of normal size, no major alterations occur in the essentially normal hæmodynamics of the lesser circulation subsequent to nitro-glycerine, when the patient is resting and at ease. During moderate exercise after nitro-glycerine there are no systematic changes in cardiac output, effective forward left ventricular work, or stroke work, but the same amount of exercise that before the administration of the drug precipitated gross left ventricular failure may be tolerated with no signs of pulmonary venous hypertension (Fig. 2).

Nitro-glycerine appears to improve the work capacity of the left ventricle, possibly by increasing coronary blood flow. 
The authors are greatly indebted to Prof. S. A. Jervell and C. Müller for the unfailing interest during the work and to Prof. J. McMichael for his valuable advice during the preparation of the paper.

\section{REFERENCES}

Amundsen, P. (1956). Second Europ. Congr. Cardol., Stockholm, Abstracts of Papers, p. 38.

Brandfonbrener, M., Landowne, M., and Shock, N. W. (1955). Circulation, 12, 557.

Epps, R. G., and Adler, R. H. (1953). Brit Heart J., 15, 298.

Goldberger, H., Dickens, J., Raber, G., and Hayes jr., E. (1957). Amer. Heart J., 53, 579.

Gorlin, R., Lewis, B. M., Haynes, F. W., Spiegel, R. J., and Dexter, L. (1951). Amer. Heart J., 41, 834.

-, Sawyer, C. G., Haynes, F. W., Goodale, W. T., and Dexter, L. (1951). Amer. Heart J., 41, 192.

Gregg, D. E. (1950). Coronary Circulation in Health and Disease. Philadelphia.

Lewis, B., Houssay, H. E. J., Haynes, F. W., and Dexter, L. (1953). Circ. Research, 1, 312.

Refsum, H. E., and Sveinsson, S. L. (1956). Scand. J. clin. Lab. Invest., 8, 67.

Russek, H. I., Urbach, K. F., and Zohman, B. L. (1955). J. Amer. med. Assoc., 158, 1017.

Sarnoff, S. J., and Berglund, E. (1954). Circulation, 9, 706.

Wayne, E. J., and Laplace, L. B. (1933-34). Clin. Science, 1, 103.

Werkö, L., Varnarnauskas, E., Eliasch, H., Lagerloef, H., Senning, A., and Thomasson, B. (1953). Circ. Research, 1, 337. 